Original Articles

\title{
Spectrum of Malignant Lymphoma in Sarawak General Hospital
}

\author{
Suat-Cheng Peh ${ }^{1)}$, Henry R Gudum ${ }^{2)}$, Yan-Chin Tai ${ }^{3)}$, \\ Fei-Ling Wong ${ }^{4)}$ and Jamil Dolkadir ${ }^{5}$ ) \\ ${ }^{1)}$ Departments of Pathology, University of Malaya, Kuala Lumpur \\ ${ }^{2}$ University of Malaysia, Sarawak \\ ${ }^{3}$ Departments of Pathology, University of Malaya, Kuala Lumpur \\ ${ }^{4}$ Departments of Pathology, University of Malaya, Kuala Lumpur \\ ${ }^{5}$ Sarawak General Hospital, Kuching, Malaysia
}

Recent epidemiological studies reported changing trend of lymphoid neoplasia in the past few decades. Previous study of lymphomas from East Malaysia from 1981 to 1983 showed a pattern similar to other Asian countries, except for low incidence of peripheral T-cell lymphoma in Sarawak. Current study analyzed materials from 1996 to 1998, with the aim to elucidate possible change in disease pattern, if any, in Sarawak 15 years later. A total of 70 re-confirmed lymphoma cases were classified using WHO proposed list of lymphoid neoplasms. There were 61 (87. 1\%) non-Hodgkin's lymphoma (NHL) and 9 (12.9\%) Hodgkin's lymphoma (HL), and NHL: HL ratio was $7: 1$. Diffuse large B-cell lymphoma was the most common subtype of NHL (62.3\%). There was only one case of T-NHL, lymphoblastic type in the series. The number of Chinese patients in this series was relatively low. Overall EBV association was $8.2 \%$ in NHL (60\% in Burkitt's type) and 33.3\% in HL. Majority of the extra-nodal lymphoma was from gastrointestinal tract $(14 / 35,40.0 \%)$, of which 10 were from the intestines. In conclusion, current study showed extremely low incidence of T-NHL and low EBV association in both NHL and HL. In addition, intestinal lymphomas constitute a large proportion of extra-nodal cases.

Key words EBV, lymphoma, Sarawak

\section{INTRODUCTION}

Studies on lymphoid neoplasm showed variation between the pattern of incidence in Western and Asian countries, suggesting the interplay between inherited and environmental factors in lymphomagenesis ${ }^{1,2}$. The incidence of Hodgkin's lymphoma (HL) was found to be higher in North America and Europe as compared to Asia, where the incidence rate is about 3 per 100,000 person-year in North America, but only 0.5 in parts of $\mathrm{Asia}^{3}$. Variation is noticed within the non-Hodgkin's lymphoma (NHL) subtypes, where follicular lymphomas are more prevalent in Western countries, while high-grade diffuse lymphomas are more common in $\mathrm{Asia}^{4-8}$. Recent reports also indicated changing trends in both HL and NHL. The incidence of

\footnotetext{
Received: August 1, 2000

Revised : October 11, 2000

January 16, 2001

Accepted: January 19, 2001
}

HL decreased slightly in recent years, which was partly attributed to shift of diagnosis from HL to $\mathrm{NHL}^{3}$. On the other hand, NHL is on rise for the past 15 years $^{9-11}$. It was believed that the increment is partly due to emergence of acquired immunodeficiency syndrome-related $\mathrm{NHL}^{12}$, and to a lesser extent by diagnostic improvements ${ }^{3}$. Exposure to occupational chemicals, such as pesticides, organic solvents, and hair dyes had been identified as possible causes of $\mathrm{NHL}^{10,13}$.

Epidemiological study of lymphomas in Malaysia, a multi-ethnic community is of paramount interest to inspect the variations in the occurrence of lymphomas among different ethnic groups. Previous study showed that Chinese ethnic group in Malaysia has an overall higher incidence rate of lymphoma ${ }^{14}$. However, other studies showed that the incidence rate of lymphoma among Malay ethnic group has been increasing for the past 25 years, especially Malay females ${ }^{11}$, while classical HL was found to be more prevalent among Indians ${ }^{15}$.

A previous study of lymphomas from East 
Malaysia, which included both Sarawak and Sabah for a period of 3 years from 1981 to 1983 showed that the pattern of lymphomas in East Malaysia conformed to the general pattern in Asia ${ }^{16}$. However, one distinct pattern of lymphoma in Sarawak was the relatively low prevalence of T-NHL as compared to Sabah and West Malaysia. Current study of Sarawak cases from 1996 to 1998 aims to investigate if any changes in the spectrum of lymphoma have taken place more than a decade later.

\section{MATERIALS AND METHODS}

\section{Tissues}

Formalin-fixed, paraffin-embedded tissues were obtained from the archives of the Department of Pathology, Sarawak General Hospital. A total of 79 biopsies from 78 patients were retrieved from 1996 to 1998. The hematoxylin and eosin-stained slides of these cases were reviewed by the pathologist (SCP). The confirmed lymphoma cases were then classified according to the new WHO proposed list of lymphoid neoplasms, circulated to members of both the Society of Hematopathology and the European Association of Hematopathology ${ }^{17}$. Serial sections were immunophenotyped with a panel of antibodies, and probed for the presence of Epstein-Barr virus (EBV) infection by in situ hybridization method for EBV early nuclear RNA (EBER). Cases of Sarawak lymphoma from earlier series (1981-83), which were previously classified using the Revised EuropeanAmerican Lymphoma Classification of lymphoid neoplasm were re-categorized according to the new WHO proposed list of lymphoid neoplasm for the purpose of comparison in this study.

\section{Immunohistochemical staining}

Immunohistochemical stain was performed on serial sections of $4 \mu \mathrm{m}$ with a panel of antibodies, mostly from Dako (Denmark) unless otherwise specified. Monoclonal antibodies to CD3 and CD20 (L26) were used as routine, with subsequent staining with additional antibodies to assist lymphoma subtyping whenever deemed necessary. These included CD5 (Novocastra, United Kingdom), CD15 (Leu-M1, Becton-Dickinson, USA), CD21, CD23 (Novocastra, United Kingdom), CD30 (BerH2), CD43 (MT1, a gift from S. Poppema), CD56 (Novocastra, United Kingdom), CD57, CD79a, Ki67, Bcl-2 and anaplastic lymphoma kinase (ALK).
Other antibodies such as epithelial membrane antigen (EMA), S-100 protein, cytokeratin (MNF116), Mic 2, melanoma antigen (HMB45) and vimentin were used when deemed necessary to reconfirm or exclude the cases.

Antigen epitope retrieval procedures, such as proteolytic pretreatment, microwave heat-inducing methods were carried out accordingly for optimal results. A standard three-step immunoenzymatic staining method was used to localize the antigens. Peroxidase-labeled avidin-biotin complex system (Dako, Denmark) and three, 3'-diaminobenzidine tetrahydrochloride chromogens (Dako, Denmark) were employed for color development. The tissues were then slightly counterstained with hematoxylin.

\section{In situ hybridization}

The presence of EBV was detected by in situ hybridization (ISH) technique. Fluoroisothiocynate (FITC)-conjugated EBV peptide nucleic acid (PNA) probes (Y 5200, Dako, Denmark) were hybridized to EBERs. Alkaline phosphatase-conjugated rabbit anti-FITC was then added followed by introduction of a substrate, 4-nitro-blue-tetrazolium chloride/5bromo-4-chloro-3-indolyl-phosphate. The tissues were counterstained with hematoxylin. A known EBV-positive nasopharyngeal carcinoma was used as an external positive control.

\section{RESULTS}

Among the 78 cases reviewed, 6 cases were excluded due to absence of tumor in the tissues, or insufficient tissue for further analysis. Two cases were diagnosed as non-lymphoma. The remaining 70 cases comprised of 61 cases (87.1\%) of NHL and 9 cases $(12.9 \%)$ of $\mathrm{HL}$. The ratio for NHL to HL was 7: 1. Table 1 summarizes the subtypes of NHL and $\mathrm{HL}$ according to age group. Among the NHL, 58 cases (95.1\%) were found to be of B-cell phenotype, and one case (1.6\%) each of $\mathrm{T}$ - and null-cell phenotype. One case remained unclassified due to failure to phenotype the tumor. Diffuse large B-cell lymphoma was found to be the most prevalent B-NHL in this series, with a total of 38 cases (62.3\%). This was followed by Burkitt's lymphoma and follicular lymphoma, with 5 cases $(8.2 \%)$ each. There was only one case of T-NHL, which was of precursor-cell lymphoblastic type. All of the main histological subtypes of HL were found in this series. There were 8 cases of classical HL (88.9\%) and one 
case of nodular lymphocyte predominance $\mathrm{HL}$ (11.1\%). The classical HL comprised of 3 cases (37.5\%) each of nodular sclerosis and mixed cellularity HL, and 1 case (12.5\%) each of lymphocyte-rich and lymphocyte-depleted HL.

There were 46 male and 23 female patients in this series, generating a male to female ratio of $2: 1$. The gender for one of the patients, presented with nodular sclerosis HL was not available from the record. The preponderance of male gender was higher in HL where 7 (77.8\%) out of 9 patients were male. The ages of the patients ranged from 4 to 85 years, with a mean of 49.9 years. The mean age for NHL was 51.7 years $(\mathrm{N}=58)$ and 34.7 years for $\mathrm{HL}$ $(\mathrm{N}=7)$. The distribution of cases by age is presented in Fig. 1. The most common age group for NHL was from 60 to 69 years old (18 cases, 31.0\%). Ethnic distribution showed 27 Iban, 22 Malay, 9 Chinese, 8 Bidayuh and 4 cases without relevant information recorded (Table 2). The Iban: Malay: Chinese : Bidayuh ratio was $3.4: 2.8: 1.1: 1$. There was wide scatter of NHL subtypes observed in Chinese and Iban, and more restricted range in Malay and Bidayuh.

EBV detection by in situ hybridization for EBER showed that most of the cases were not EBV associated. EBV was only detected in $5(8.2 \%)$ among the 61 NHL and $3(33.3 \%)$ among the $9 \mathrm{HL}$ (Table 1). Among the different subtypes of NHL, Burkitt's lymphoma (60\%) showed the highest association rate with EBV. EBV association among the ethnic groups is presented in Table 3. The association rate with EBV was found to be almost similar between Chinese (11.1\%) and Bidayuh (12.5\%). The ethnic Iban (7.4\%) has a lowest association with EBV, while the Malay has the highest association of $18.2 \%$.

There were 35 (50.0\%) biopsies from lymph nodes and 35 (50.0\%) from extra-nodal lymphoid tissues. Majority of the lymph nodes was excised from the neck and head region $(13,36.1 \%)$, and other superficial nodal groups in the inguinal and axillary regions $(12,33.3 \%)$. One was biopsied from the retro-peritoneal lymph node and the remaining 9 cases $(25.7 \%)$ were from other non-specified sites. The extranodal lymphoid tissues were from the gastrointestinal tract (14 cases, 40.0\%), tonsils (6 cases, 17.1\%), oral cavity ( 3 cases, $8.6 \%$ ) and other sites $(12,34.3 \%)$. The tumors from the gastrointestinal tracts included 4 cases from the stomach (all males, one each from Iban, Chinese, Bidayuh and Malay) and 10 cases from the intestines. There were
4 Malays ( 3 males, 1 female), 2 Iban (1 male and female each), and one male each in Chinese, Bidayuh and one non-stated.

\section{DISCUSSION}

Sarawak is the largest state in Malaysia, with a total population of $1,642,771$ according to 1991 Population and Housing Census of Malaysia ${ }^{18}$. Major ethnic groups include the Bumiputras (Iban, Malay, Bidayuh, Melanau and other minor indigenous tribes), Chinese, and others. The ethnic Iban (29.7\%) is the largest majority, followed by Chinese (27.5\%), Malay (21.6\%), Bidayuh (8.3\%), Melanau (5.8\%), and others (7.1\%). Sarawak General Hospital, Kuching is still the single major government hospital with histopathology service for the people in Sarawak.

The general pattern of lymphoma in this series appears to concur with earlier study ${ }^{16}$. The ratio of NHL to HL in both series was comparable $(7.7: 1$ and $7: 1$ ) indicating that the incidence rate of NHL and HL did not fluctuate significantly from 1980s to 1990s. NHL in Asia generally shows a particularly high prevalence of high-grade diffuse lymphoma, but low incidence of follicular lymphoma ${ }^{2,3,9}$. Both the series from Sarawak also showed that high-grade diffuse lymphoma was the most prevalent NHL subtype (Table 4). One study reported that ageadjusted incidence rate of diffuse NHL in Japan and the United States was almost similar, indicating that the true difference between Asian and North America populations lies in the low incidence of follicular NHL, rather than high incidence of diffuse $\mathrm{NHL}^{5}$. The ratio of high-grade diffuse lymphoma to follicular lymphoma was 10.2:1 and 7.6:1, for the 1980s and 1990s series respectively. The lower ratio observed in 1990s was attributed to higher occurrence of follicular lymphoma (8.2\% in 1990s series compared to $5 \%$ in 1980 s series), rather than decrease in high-grade diffuse. The ratio observed in Sarawak was intermediate among some of the Asian countries, between the low ratios of $2.8: 1$ and 4.3 : 1 in Taiwan ${ }^{7}$ and India $^{8}$ respectively, and the extreme high ratios of $25: 1$ in Korea and 24:1 in Thailand ${ }^{5}$.

Studies in Asia had revealed a higher incidence of $\mathrm{T}-\mathrm{NHL}^{19}$, especially in HTLV-1 endemic areas such as Japan $^{20}$ and some parts of Taiwan ${ }^{7}$. In non-endemic areas, higher incidence of T-NHL is attributed to the low prevalence of follicular lymphoma in $\mathrm{Asia}^{21}$. It is noteworthy that both 
Suat-Cheng Peh, H. R Gudum, Yan-Chin Tai, 48 Fei-Ling Wong and J. Dolkadir

studies reported extremely low occurrence of T-NHL in Sarawak (Table 4), and the numbers of peripheral T-NHL appeared to decline, from a total of $6.6 \%$ in 1980 s to $0 \%$ in the 1990 s. However, a study involving a larger series would be necessary to establish if this decline is statistically significant. The frequency of T-NHL in Sarawak was much lower than those reported in Thailand $(16.1 \%)^{5}$ and Singapore $(22 \%)^{22}$, which are the nearest neighbors of Malaysia. It is partly explained by low prevalence of EBVassociated T/NK lymphoma in Sarawak, which is more commonly diagnosed in Chinese ${ }^{23}$. Chinese, in general, are considered to have a higher risk of developing lymphoma and other cancers ${ }^{11,14}$. On the contrary, the number of Chinese patients was relatively low in both studies, being $18 \%$ and $12.9 \%$ in 1980s and 1990s series respectively. The percentage of Chinese lymphoma patients was lower, $10.0 \%$ $(32 / 321)$ based on estimation adjusted to ethnic population ratio: Malay $102(22 / 0.216)$, Iban 91 $(27 / 0.297)$, Bidayuh $96(8 / 0.083)$, and Chinese 32 (9/0.275), as compared to $27.5 \%$ of Chinese in the population. From the patients' records, all these Chinese patients were born and bred in Sarawak, with the exception of a male patient of 84 years who migrated to Sarawak from Peninsular Malaysia. The possible reason for the apparent lower risk of developing lymphomas in the ethnic Chinese in Sarawak is not immediately evident.

Interestingly, there are reports of high incidence of nasopharyngeal carcinomas (NPC), a closely EBV-associated cancer occurring amongst the indigenous tribes in Sarawak, where the relative frequency of NPC is higher than Chinese ${ }^{24,25}$. The type of NPC most frequently found in Sarawak are those of undifferentiated or poorly differentiated type, which are known for their association with EBV. Previous studies showed an early age of seroconversion rate of EBV and susceptibility of the people to the virus-associated malignancy ${ }^{26,27}$. However, EBV association rate of various subtypes of lymphomas in both series was not higher than most reported series in West Malaysia ${ }^{15,23}$, Asia ${ }^{28-30}$ and Western coun$\operatorname{tries}^{31,32}$, and is distinctly different from the experience of African Burkitt's lymphoma ${ }^{33}$ and HL in non-industrialized countries ${ }^{34,35}$.

Large proportion of the extranodal lesions in this series was from the gastrointestinal tract (40.0\%) with a large majority from the intestines. This observation is distinctly different from the experience in other hospitals in Malaysia. In Klang Hospital, gastrointestinal lymphoma constituted
17.4\% (4/23, 2 gastric, 2 intestine $)^{36}$ and $15.4 \%$ (12/ 78, 10 gastric and 2 intestine) in Hospital University Kuala Lumpur (unpublished data). The reason for the high incidence of intestinal lymphoma in Sarawak is not immediately apparent.

In conclusion, malignant lymphomas in Sarawak showed a characteristically low incidence of T-NHL as reported in the previous study. Contrary to speculation of high prevalence of EBV association due to the susceptibility of the people to NPC, this study reconfirms the previous observation of a relatively low EBV-association rate with various subtypes of lymphomas, and in addition, there is a relatively high incidence of primary gastrointestinal presentation.

This study was supported by Malaysian Ministry of Science, Technology and Environment IRPA research grant (06-02-03-0576).

\section{REFERENCES}

1 Magrath I: Molecular basis of lymphomagenesis. Cancer Res (Suppl) 52: 5529s-5240s, 1992.

2 Anderson JR, Armitage JO, Weisenburger DD: Epidemiology of the non-Hodgkin's lymphomas. Distribution of the major subtypes differs by geographic locations. Ann Oncol 9: 717-720, 1998.

3 Hartge P, Devesa SS, Fraumeni, JF Jr: Hodgkin's and non-Hodgkin's lymphomas. Cancer Surv 19/ 20: 423-453, 1994.

4 Ho FCS, Loke SL, Hui PK, Todd D : Immunohistological subtypes of non-Hodgkin's lymphoma in Hong Kong Chinese. Pathology 18 : 426-430, 1986.

5 Intragumtornchai $\mathrm{T}$, Wannakrairoj $\mathrm{P}$, Chaimongkol B, Bhoopat L, Lekhakula A, Thamorasit T, Suwanwela N, Suthipinthawong C, Prayoonwiwat W, Meekungwal P, Sirijerachai C, Pairojkul C: Non-Hodgkin's lymphomas in Thailand. A retrospective pathologic and clinical analysis of 1391 cases. Cancer 78: 1813-1819, 1996.

6 Harrington DS, Ye YL, Weisenburger DD, Armitage JO, Pierson J, Bast M, Purtilo DT: Malignant lymphoma in Nebraska and Guangzhou, China. Hum Pathol 18: 924-928, 1987.

7 Su IJ, Shih LY, Kadin ME, Dun P, Hsu SM: Pathologic and immunologic characterization of malignant lymphoma in Taiwan. With special reference to retrovirus-related adult T-cell lymphoma/ leukemia. Am J Clin Pathol 84: 715-723, 1985.

8 Garg A, Dawar R, Agarwal V, Rustagi RK, Kochpillai V : Non-Hodgkin's lymphoma in Northern India. A retrospective analysis of 238 cases. Cancer 56 : 972-977, 1985. 
9 Devesa SS, Fears T: Non-Hodgkin's lymphoma time trends. United States and International data. Cancer Res (Suppl) 52: 5432s-5440s, 1992.

10 Pearce $N$, Bethwaite $P$ : Increasing incidence of non-Hodgkin's lymphoma: Occupational and environmental factors. Cancer Res (Suppl) 52 : 5496s5500s, 1992.

11 Seow A, Lee J, Sng, I, Fong CM, Lee HP: NonHodgkin's lymphoma in an Asian population. Cancer 77: 1899-1904, 1996.

12 Gaidano G, Carbone A, Dalla-Fevera, R: Genetic basis of acquired immunodeficiency syndromerelated lymphomagenesis. J Natl Cancer Inst Monogr 23: 95-100, 1998.

13 Scherr PA, Hutchison GB, Neiman RS: NonHodgkin's lymphoma and occupational exposure. Cancer Res (Suppl) 52 : 5503s-5509s, 1992.

14 Bosco J, Cherian HP, Lin HP, Pang T : Leukemia and lymphoma in Malaysia. Leuk Res 9: 789-791, 1985.

15 Peh SC, Looi LM, Pallesen G : Epstein-Barr virus (EBV) and Hodgkin's disease in a multi-ethnic population in Malaysia. Histopathology $30: 227-$ 233, 1997.

16 Chai SP, Peh SC, Lim MY, Gudum HR : Pattern of malignant lymphoma in East Malaysian patients as experienced in University Hospital, Kuala Lumpur. Malays J Pathol 21 : 45-50, 1999.

17 Peh SC, Poppema S : Consensus report. Histopathological reporting of malignant lymphoma. Malays J Pathol 21 : 63-67, 1999.

18 Population and Housing Census of Malaysia 1991 : State Population Report - Sarawak. Department of Statistic Malaysia, 1995.

19 Pallesen G, Hamilton-Dutoit SJ, Zhou X: The association of Epstein-Barr virus (EBV) with $\mathrm{T}$ cell lymphoproliferations and Hodgkin's disease: two new developments in the EBV field. Adv Cancer Res 62: 179-239, 1993.

20 Hinuma $\mathrm{Y}$, Komoda $\mathrm{H}$, Chosa $\mathrm{T}$, Kondo $\mathrm{T}$, Kohakura M, Takenaka T, Kikuchi M, Ichimaru M, Yunoki K, Sato I, Matsuo R, Takiuchi Y, Uchino $\mathrm{H}$, Hanaoka M: Antibodies to adult T-cell leukemia virus associated antigen (ATLA) in sera from patients with ATL and controls in Japan : a nationwide sero-epidemiological study. Int J Cancer 29 : 631-635, 1982.

21 Shih LY, Liang DC : Non-Hodgkin's lymphoma in Asia. Hematol Oncol Clin North Am 5: 983-1001, 1991.

22 Sng I, Levin A, Jaffe ES, Ng HW, Sim CS, Blattner WB: T-cell lymphoma in Singapore: pathology, clinical findings and association with HTLV-1 antibodies. Histopathology 21 : 101-113, 1992.

23 Peh SC, Sandvej K, Pallesen G : Epstein-Barr virus
(EBV) in Malaysian upper-aerodigestive-tract lymphoma: incidence and subtype. Int $\mathbf{J}$ Cancer 61: 327-332, 1995.

24 Muir CS: Nasopharyngeal carcinoma in nonChinese populations with special reference to South-East Asia and Africa. Int J Cancer 8: 351363, 1971.

25 Yadav M, Tan MK, Singh P, Dharmalingam SK : Nasopharyngeal carcinoma in Malaysians under the age of 20 years. Clin Oncol 10: 353-361, 1984.

26 Tan DSK, Henle G: Antibodies to EBV related antigens in West Malaysian children. Med $\mathbf{J}$ Malaya 27: 27-29, 1972.

27 Yadav MS, Malliga N, Ablashi DV : Development of immunity to Epstein-Barr virus in Malaysian children. Microbiologica 10: 29-35, 1987.

28 Paulino AFG, Paulino-Cabrera E, Weiss LM, Medeiros LJ : Hodgkin's disease in the Philippines. Mod Pathol 9: 115-119, 1996.

29 Chao TY, Wang TY, Lee WH: Association between Epstein-Barr virus and Burkitt's lymphoma in Taiwan. Cancer 80: 121-128, 1997.

30 Tomita Y, Ohsawa M, Mishiro Y, Kubo T, Maeshiro N, Kojya S, Noda Y, Aozasa K: The presence and subtype of Epstein-Barr virus in $B$ and $T$ cell lymphomas of the sino-nasal region from Osaka and Okinawa districts of Japan. Lab Invest 73 : 190-196, 1995.

31 Leoncini L, Spina D, Nyong'o A, Abinya O, Minacci C, Disanto A, De Luca F, De Vivo A, Sabattini E, Poggi S, Pileri S, Tosi P : Neoplastic cells of Hodgkin's disease show differences in EBV expression between Kenya and Italy. Int $\mathbf{J}$ Cancer 65: 781-784, 1996.

32 Andriko JA, Aguilera NS, Nandedkar MA, Abbondanzo SL: Childhood Hodgkin's disease in the United States: an analysis of histologic subtypes and association with Epstein-Barr virus. Mod Pathol 10: 366-371, 1997.

33 Magrath I: The pathogenesis of Burkitt's lymphoma. Adv Cancer Res 55 : 133-270, 1990.

34 Ambinder RF, Browning PJ, Lorenzana I, Leventhal BG, Cosenza H, Mann RB, MacMahon EM, Medina R, Cardona V, Grufferman S, et al: Epstein-Barr virus and childhood Hodgkin's disease in Honduras and the United States. Blood 81: 462467, 1993.

35 Chang KL, Albujur PF, Chen YY, Johnson RM, Weiss LM : High prevalence of Epstein-Barr virus in the Reed-Sternberg cells of Hodgkin's disease occurring in Peru. Blood 81: 496-501, 1993.

36 Peh SC, Kim LH, Thanaletchimy N, Chai SP, Poppema $\mathrm{S}$ : Spectrum of malignant lymphomas in Klang Hospital. Malays J Pathol, in press. 